\title{
Erektil disfonksiyon tedavisinde penil protez implantasyonunun uzun dönem klinik sonuçları
}

\section{The long term clinical results of penile prosthesis implantation in the treatment of erectile dysfunction}

\author{
Bilali Habeș Gümüș, Ali Can Albaz
}

\section{öz}

AMAÇ: Bu çalışmanın amacı, organik nedenli erektil disfonksiyon (ED) tanılı hastaların tedavisi için kliniğimizde uygulanan penil protez implantasyonun uzun dönem klinik sonuçlarını değerlendirmektir.

GEREÇ ve YÖNTEMLER: Kliniğimizde organik ED tanısı ile penil protez implantasyonu yapılan ve üzerinden 60 ay ve üzeri süre geçmiș olan, ulaşlabilen 52 hasta içerisinden çalışmaya katılmayı kabul eden 34 hastaya ait veriler retrospektif olarak incelendi. Hastaların demografik verileri, uygulanan protez tipleri, peroperatif ve postoperatif komplikasyonla$\mathrm{r} 1$, post operatif dönemde kendisinin ve eşinin memnuniyet durumu değerlendirildi.

BULGULAR: Penil protez implantasyonu yapılan 34 olgunun yaş ortalaması $61,97 \pm 10,55$ yil ve ortalama vücut kitle indeksleri $27,55 \pm 4,33 \mathrm{~kg} /$ m2 olarak saptandı. Hastaların 23 'ünde $(\% 69,6)$ sigara kullanım öyküsü mevcuttu. Malleable protez konulan $15(\% 44,1)$ hasta iken, 14 (\%41,1) hastaya iki parçalı penil protez, geri kalan beş $(\% 14,7)$ hastaya da üç parçalı protez yerleștirildi. Penil protez cerrahisi sefazolin ve gentamisin profilaksisi ile 34 hastada penoskrotal insizyonla gerçekleştirildi. Hiçbir hastada peroperatif komplikasyon yaşanmadı. Bir hastada penil gerginlik/ağrn, iki hastada insizyon yerinde antibiyoterapi ile düzelen lokalize enfeksiyon ve bir hastada mekanik problem nedeniyle re-implantasyon gerçekleştirildi. İki hastada protez enfeksiyonu nedeniyle penil protez çıkartıldı. Ortalama takip süresi $86,47 \pm 31,78$ ay olan hastaların $\% 82,4 ’ \ddot{u}$, eşlerinin $\% 70,5$ 'i penil protezden memnun olduğunu belirtti.

SONUÇ: Penil protez implantasyonu, erektil disfonksiyon tedavisinde 3. basamak tedavi olarak başvurulan invazif ve etkili bir tedavi biçimidir. Yüksek oranlarda hasta ve eş memnuniyeti sağlayan bu yöntemde, uygun cerrahi prosedürlere rağmen enfeksiyon en sık görülen ciddi bir komplikasyondur.

Anahtar Kelimeler: Erektil disfonksiyon, cerrahi, tedavi, penil protez, komplikasyon

\section{ABSTRACT}

INTRODUCTION: The aim of this study is to evaluate the long-term clinical outcomes of penile prosthesis implantation in our clinic for the treatment of patients with organic erectile dysfunction (ED).

MATERIAL and METHODS: We retrospectively analyzed the data of 34 patients who agreed to participate in the study from 52 accessible patients who were diagnosed with organic ED in our clinic and who had undergone the penile prosthesis implantation for 60 months or more. Patient demographic data, the type of prostheses, peroperative and postoperative complications, postoperative couples' satisfaction were evaluated.

RESULTS: The mean age of the 34 patients with penile prosthesis implantation was $61.97 \pm 10.55$ years and the mean body mass index was $27.55 \pm 4.33 \mathrm{~kg} / \mathrm{m} 2.23$ of the patients $(69.6 \%)$ had a history of smoking. The malleable prosthesis was implanted to 15 patients (44.1\%), the 2-piece penile prosthesis to $14(41.1 \%)$ patients and the 3 -piece prosthesis to the remaining $5(14.7 \%)$ patients. Penile prosthesis was performed with cefazolin and gentamicin prophylaxis in 34 patients by penoscrotal incision. There were no peroperative complications in any patient. Penile tension/pain in one patient, localized infection in 2 patients with an on site antibiotherapy and re-implantation due to a mechanical problem in 1 patient. Penile prosthesis was removed due to prosthetic infection in two patients. The mean follow-up was $86.47 \pm 31.78$ months and approximately $82.4 \%$ of patients and $70.5 \%$ of their partners were satisfied with the surgical results of the penile prosthesis operation.

CONCLUSION: Penile prosthesis implantation is an invasive and effective form of treatment as a third-line treatment in the treatment of erectile dysfunction. In this method of providing patient and co-satisfaction at high rates, infection is the most common serious complication, despite appropriate surgical procedures.

Keywords: Erectile dysfunction, surgery, treatment, penile prosthesis, complication
Manisa Celal Bayar Üniversitesi Tıp Fakültesi, Üroloji Anabilim Dalı, Manisa

Yazışma Adresi / Correspondence:

Arș. Gör. Dr. Ali Can Albaz

Manisa Celal Bayar Üniversitesi, Hafsa Sultan Hastanesi,

Yunusemre, Manisa - Türkiye

Tel. + +905059129003

E-mail: alicanalbaz@hotmail.com

Geliş / Received: 22.11.2017; Kabul / Accepted: 07.12.2017

\section{GíRiș}

Erektil disfonksiyon (ED) prematür ejakulasyondan sonra en sık görülen erkek cinsel fonksiyon bozukluğu olup ${ }^{[1]}$ "bir erkeğin en az altı ay süre ile seksüel ilişki için yeterli penis ereksiyonunu sağlama ve/veya sürdürmede yetersizliği” olarak tanımlanmaktadır. ${ }^{[2]}$ ED son yıllara kadar genellikle psikolojik kökenli bir hastalık olarak tanımlanmasına karşılık, günümüzde ED’nin kökeninde $\% 75$ oranında 
organik nedenin bulunduğu kabul edilmektedir. ${ }^{[3]}$ Türk Androloji Derneği tarafindan 2014 yılında ülkemizde ED prevalansı ve bağlantılarını araştırma amaçlı yapılan toplum esaslı bir çalışmada prevalans $\% 33$ olarak bulunmuş, bunun $\% 76,9$ 'si hafif, $\% 16,3$ 'i orta, $\% 5,7$ 'i de tam derecede ED olarak bildirilmiştir. ${ }^{[4,5]}$

Yaşam tarzı değişiklikleri, ağız yoluyla veya intrakavernöz enjeksiyonla uygulanan medikal tedavi seçeneklerini içeren birinci ve ikinci basamak konservatif tedaviler, günümüzde ED'li hastalara ilk uygulanan yöntemlerdir. Fosfodiesteraz Tip-5 inhibitörleri, intrakavernöz enjeksiyonlar, intraüretral alprostadil ve vakum cihazları, hastaların $\% 80$ gibi bir oranda tedaviyi bırakmaları nedeniyle başarısız olabilir. ${ }^{[6,7]}$

Oral ve cerrahi dışı tedavilerden yanıt alınamayan veya herhangi bir nedenle bu tedavileri kullanamayan erektil disfonksiyonlu (ED) hastalarda üçüncü basamak tedavi olarak penil protez implantasyonu önerilmektedir. ${ }^{[8]}$ Son yıllarda komplikasyon ve mekanik cihaz hasarı oranlarını azaltmaya ve hasta/eş memnuniyetini arttırmaya yönelik birçok modifikasyon geçiren şişirilebilir protezler, günümüzde hâlen ED tedavisinde son basamak olarak yaygın kullanım alanı bulmaktadır. ${ }^{[9,10]}$

Bizim bu çalışmamızdaki amacımız, birinci ve ikinci basamak tedavilere yanıt vermeyen organik nedenli ED'li hastalara uyguladığımız penil protez implantasyonuna ait hasta ve eş memnuniyetine ait sonuçlarımızı sunmaktır.

\section{GEREÇ VE YÖNTEM}

Kliniğimizde Ocak 2004 ile Ağustos 2014 tarihleri arasında, bükülebilir veya şişirilebilir penil protez implantasyonu uygulanan organik nedenli ED'si bulunan ve ulaşılabilen 52 hastadan, telefon ile ulaşılabilen ve/veya karşılıklı görüşme olanağı sağlanan ve çalışmaya dahil olmayı kabul eden 34 hastaya ait veriler retrospektif olarak değerlendirilmiştir.

Hastalara operasyon öncesinde işlem ile ilgili genel bilgiler, meydana gelebilecek komplikasyonlar ve alternatif tedavi yöntemleri anlatılmıştır. Hastalar ve eşleri bilgilendirilmiş, onamları alınmıştır. Hastalara yapılan bilgilendirmenin ardından, mental durumlarına, el becerilerine ve üretralarında darlık olup olmamasına göre, şişirilebilir veya bükülebilir penil protez tipi önerilmiştir. Hastaların, 21'i spinal anestezi altında ve 13 'ü de genel anestezi altında olmak üzere, pubik bölgeleri traşlandıktan sonra povidon-iyodin solüsyonuyla 10 dakika boyunca genital bölge yıkanmıştır. Tüm hastalara, aynı zamanda profilaksi amaçlı intravenöz sefazolin ve gentamisin uygulanmıştır. Ardından, supin pozisyonda $18 \mathrm{fr}$ foley sonda takıldıktan sonra penoskrotal bölgeden yaklaşı $3 \mathrm{~cm}$ 'lik cilt insizyonuyla korpus kavernozumlara ulaşılıp 2 cm'lik bilateral korporotomi gerçekleştirilmiştir. Sonrasında, Hegar dilatatörler kullanılarak ve korpus kavernozumda protezin yerleştirileceği alanlar oluşturularak, uygun uzunlukta silindir seçimi için ölçümler yapılmıştır. Tüm bu işlemler yapılırken, korpus kavernozumlar gentamisin içeren solüsyonlarla yıkanmıştır. Korpus kavernozumda dorsal sinirin lateraline destek süturleri konulup şişirilebilir protez yerleştirilen hastalara, kraniyo-kaudal pozisyonda fasya transversalisin arkasına $100 \mathrm{~mL}$ izotonik ile doldurulmuş rezervuar yerleştirilmiştir. Cerrahi alan hazırlandıktan sonra silindirler, retraksiyon için destek sutürleri kullanılarak yerleştirilmiştir. Silindirler hemen doldurularak, fonksiyonel ve kozmetik olarak bir problem olup olmadığı değerlendirilmiştir. Çok parçalı protez takılan hastalara, skrotumda sağ tarafa subdartos poş oluşturularak pompa yerleştirilmiştir. Hidrolik test yapıldıktan sonra da korporotomiler, daha önce konulmuş $2 / 0$ vicryl destek sutürleriyle kapatılmıştır. Cilt altı ve cilt $2 / 0$ rapid vicryl ile sutüre edilerek işleme son verilmiştir.

Operasyondan altı hafta sonra tüm hastalara protez kullanma eğitimi verilerek, hastaların penis protezleri aktive edilmiştir. Hastaların cinsel ilişkiye girmeleri önerilmiştir. Postoperatif enfeksiyona karşı, altı hafta boyunca oral siprofloksasin tedavisine devam edilmiştir.

Penis protez takılma işleminin üzerinden 60 ay ve üzeri geçmiş olan hastalar çalışmaya dahil edildi. Demografik veriler olarak hastanın yaşı, vücut kitle indeksi ve medeni durumu, hangi tip protezin konulduğu, postoperatif komplikasyonlar ve hastaların ve eşlerinin memnuniyet düzeyleri araştırıldı. Hastalarımıza Modifiye EDITS (Erectile Dysfunction Inventory of Treatment Satisfaction Questionnaire) hasta sorgulama formu doldurtularak, kendilerinin ve eşlerinin memnuniyet düzeyleri araştırıldı. Genel memnuniyet 5 puanlı ölçekte değerlendirilmiştir; 1- hiç memnun değil, 3- kısmen memnun ve 5- oldukça memnun.

Olguların modifiye EDITS hasta sorgulama formu soruları:

1. Genel olarak, penil protezinizden memnun musunuz?

2. Penil protez beklentilerinizin ne kadarını karşıladı?

3. Penil protez sürekli kullanım için ne kadar uygun?

4. Penil protezi kullanmak sizin için kolay oluyor mu?

5. Cinsel birleşme esnasındaki hissetme (zevk) yetinize güveniniz nasıl?

6. Eşinizin memnuniyeti nasıl? 
$\mathrm{Bu}$ soruların dışında, ejakulasyon miktar ve süresinde preoperatif döneme göre değişiklik olup olmadığı, dört hafta içindeki cinsel ilişkiye girme sayısı ve hastanın protez operasyonu yaptırmayı başkasına tavsiye edip etmeyeceği de soruldu. Operasyon sonrası hasta ve partner memnuniyeti, birebir görüşme (yüz yüze ve/veya telefon görüşmesi) ile değerlendirildi.

Çalışmamızın verileri, Microsoft Excel programının fonksiyon hesaplamaları kullanılarak değerlendirildi. Elde edilen sonuçlarla tablo oluşturuldu.

\section{BULGULAR}

Hastaların ortalama yaşları $61,97 \pm 10,55$ yıl olup 26 ile 83 yıl arasında değişmekteydi. Hastaların ortalama vücut kitle indeksleri $27,55 \pm 4,33 \mathrm{~kg} / \mathrm{m} 2$ olarak saptand. Ortalama takip süresi $86,47 \pm 31,78$ aydır. Genel olarak sağlık durumu hakkında \%14,7'si çok iyi olduğunu, \%52,9'u iyi olduğunu, \%26,4'ü orta, \%5,8'i ise kötü olduğunu belirttiler. Toplam 34 hastadan; $15(\% 44,1)$ hastaya bir, $14(\% 41,1)$ hastaya iki, geri kalan beş $(\% 14,7)$ hastaya da üç parçalı protez yerleştirildi (Tablo 1). Hastaların 20'si $(\% 58,8)$ protezi rahat kullanabildiğini belirtirken, 14 ü $(\% 41,1)$ rahat kullanamadığını belirtti (Tablo 2). Bu 14 hastadan birinde protezde mekanik problem nedeniyle re-implantasyon yapılırken, iki hastada protez enfeksiyonuna bağlı protez çıkarılması işlemi uygulandı. Altı hasta, pompanın kullanımında oluşan cilt ağrısına sekonder zorluk olduğunu, kalan beş hasta ise pompa ile ilgili problem yaşadığını belirtti. $\mathrm{Bu}$ problemlerin, protezi "inflatable" hale getirirken mekanizmayı bulmaktaki güçlüğe, pompanın sert olmasına ve sertleşmenin geç oluşmasına bağlı olduğu görülmektedir. İki hastada, protez enfeksiyonu nedeniyle penil protez çıkartıldı. Bu hastalardan birinin çıkarılma zamanı protez implantasyonu sonrası 7. ay, diğerinin ise postoperatif 22. ay idi. Postoperatif 3. aydan daha geç başlangıçlı protez enfeksiyonları, geç enfeksiyon olarak kabul edildi. Hastaların 10 'u $(\% 29,4)$ protez kullanımı sırasında ağrı olduğunu belirtti (Tablo 3). Ejakülasyon miktar ve süresinde ameliyat öncesine göre artış oldu diyen hasta $14(\% 41,1)$ iken, dört hasta $(\% 11,7)$ azaldığını, üç hasta da $(\% 8,8)$ ejakülasyonun olmadığını söyledi; kalan 13 hastada $(\% 38,2)$ ejakulasyon miktarında değişim saptanmadı (Tablo 4). Hastalardan beşi $(\% 14,7)$ ortalama dört hafta içinde hiç cinsel ilişkide bulunmaz iken, 17 hasta (\%50) 1-5 kez, dokuz hasta $(\% 26,4) 5-10$ arası, üç hasta ise $(\% 8,8) 10$ ve üzeri sayıda cinsel ilişkide bulunduğunu belirtti (Tablo 5). Hastaların dokuzu $(\% 26,4)$ dört hafta içinde cinsel ilişki performansından çok memnun olduğunu, 12'si $(\% 35,2)$ memnun olduğunu, yedisi $(\% 20,5)$ orta düzeyde memnun olduğunu, altı hasta $(\% 17,6)$ ise memnun olmadığını belirtti (Tablo
Tablo 1. Tek parçalı/ 2 parçalı/ 3 parçalı

\begin{tabular}{cccc}
\hline Tek parçalı & 2 parçalı & 3 parçalı & Toplam \\
\hline 15 & 14 & 5 & 34 \\
44,11 & 41,17 & 14,70 & 100 \\
\hline
\end{tabular}

Tablo 2. Protezi rahat kullanabiliyor musunuz?

\begin{tabular}{ccc}
\hline Kullanabiliyorum & Kullanamıorum & Toplam \\
\hline 20 & 14 & 34 \\
58,82 & 41,17 & 100 \\
\hline
\end{tabular}

Tablo 3. Protez kullanımı sırasında ağrı oluyor mu?

\begin{tabular}{ccc}
\hline Evet & Hayır & Toplam \\
\hline 10 & 24 & 34 \\
29,41 & 70,58 & 100 \\
\hline
\end{tabular}

Tablo 4. Ejakülasyon miktar ve süresinde ameliyat öncesine göre değişim oldu mu?

\begin{tabular}{ccccc}
\hline \multirow{2}{*}{ Arțşoldu } & Değişmedi & Azalma oldu & $\begin{array}{c}\text { Ejakulasyon } \\
\text { yok }\end{array}$ & Toplam \\
\hline 14 & 13 & 4 & 3 & 34 \\
41,17 & 38,23 & 11,76 & 8,82 & 100 \\
\hline
\end{tabular}

Tablo 5. Dört hafta içinde kaç kez cinsel ilişkide bulundunuz?

\begin{tabular}{ccccc}
\hline Hiç & $1-5$ arası & $5-10$ arası & 10 ve üzeri & Toplam \\
\hline 5 & 17 & 9 & 3 & 34 \\
14,70 & 50 & 26,47 & 8,82 & 100 \\
\hline
\end{tabular}

Tablo 6. Dört hafta içindeki cinsel ilişkide ne sıklıkla memnun oldunuz?

\begin{tabular}{ccccc}
$\begin{array}{c}\text { Memnun } \\
\text { değil }\end{array}$ & $\begin{array}{c}\text { Orta } \\
\text { memnuniyet }\end{array}$ & Memnun & $\begin{array}{c}\text { Çok } \\
\text { memnun }\end{array}$ & Toplam \\
\hline 6 & 7 & 12 & 9 & 34 \\
17,64 & 20,58 & 35,29 & 26,47 & 100 \\
\hline
\end{tabular}

6). Hasta eşlerinin 10 'u $(\% 29,4)$ dört hafta içindeki cinsel ilişkiden memnun olmadığını, 24’ü $(\% 70,5)$ ise memnun olduklarını belirtti (Tablo 7). Hastaların 26'sı $(\% 76,4)$ bu tecrübeden sonra tekrar başa dönse protez operasyonu yaptırmayı isterken, sekizi $(\% 23,5)$ protez operasyonu yaptırmayı istemeyeceğini belirtti (Tablo 8). 
Tablo 7. Dört hafta içindeki cinsel ilişkide eşiniz ne sıklıkla memnun oldu?

\begin{tabular}{ccc}
\hline Memnun değil & Memnun & Toplam \\
\hline 10 & 24 & 34 \\
29,41 & 70,58 & 100 \\
\hline
\end{tabular}

Tablo 8. Tekrar başa dönse protez yaptırır mı?

\begin{tabular}{ccc}
\hline Evet & Hayır & Toplam \\
\hline 26 & 8 & 34 \\
76,47 & 23,52 & 100 \\
\hline
\end{tabular}

\section{TARTIȘMA}

Türkiye'de ED insidansı ile ilgili yapılmış bir çalışmada; 40 yaşın üzerindeki erkeklerde genel erektil disfonksiyon insidansı $\% 33$ olarak saptanmıştır. ${ }^{[4]}$ Yapılan diğer bir çalışmada ise; 2025 yılında Avrupa'da 40 yaşın üzerinde \%48'in üzerinde ED beklenmektedir. ${ }^{[11]}$

Kliniğimizde ED tedavisi için, Avrupa Üroloji Birliği'nin güncel kılavuzunda yer alan algoritma kullanılmaktadır. ${ }^{[12]}$ Organik kaynaklı ED tanısı konulan hastalarımıza, öncelikle oral fosfodiesteraz Tip 5 inhibitörü ve vakum cihazları önerilmekte; bu tedavilerden fayda görmeyen ve/veya yan etkiler oluşan hastalarımıza, ikinci basamak tedavi seçeneği olarak, intrakavernozal enjeksiyon önerilmektedir. Bu tedavi seçeneklerinden fayda görmeyen ve/veya tedaviler sırasında yan etkiler meydana gelen hastalarımıza, penil protez implantasyonu önermekte ve uygulamaktayız.

Erektil işlev bozukluğu tedavi seçenekleri arasında, penil protez implantasyonunun en başarılı ve memnuniyet oranı en yüksek tedavi seçeneği olduğu literatürde bildirilmiştir. ${ }^{[13]}$ Tüm protez tiplerinin hasta memnuniyetini etkileyecek farklı üstünlükleri ve olumsuz yanları mevcuttur. ${ }^{[14]}$ Bükülebilir protezlerin giyinme ve işeme sırasında aşağıya, ilişki sırasında ise yukarıya bükülmeyi sağlayan yapısı vardır. Bu protez tipinin üstünlükleri; mekanik hasara yol açacak parçalar içermemesi, kolay ve kısa sürede yerleştirilmesi ve ucuz olmasıdır. Bununla beraber sürekli rijit kalmasından ötürü sonradan gerekebilecek endoskopik işlemler için güçlük çıkarması gibi bir dezavantajı vardır. ${ }^{[15]}$ Şişirilebilir protezlerin ise kozmetik ve doğal bir ereksiyonu taklit eder gibi penil uzunluk ve kalınlıkta artış olması gibi avantajları vardır. ${ }^{[15]} \mathrm{Bu}$ protez tipinde en önemli olumsuzluk mekanik hasardır. Klinik pratiğimizde biz, şişirebilir penis protezi için kontrendikasyon olmayan tüm hastalarımıza bu tip protezi önermekteyiz. Serimizde "malleable" protezin sayısal olarak fazla olması, takip süresi 60 aydan fazla olan hastaları içermesindendir. Ayrıca, tüm penil protezler hakkında bilgilendirme yapılıp hasta tercihini göz önüne almaktayız. Çalışmamızın ana amacı, erektil işlev bozukluğu nedeniyle penil protez implantasyonu yapılan hastalarda yan etki ve memnuniyeti değerlendirmektir. Literatürde protez memnuniyetsizliğinin esas sebebi, enfeksiyon, erozyon veya mekanik hasar nedeniyle protez çıkarılması olarak bildirilmektedir. ${ }^{[9]}$ Ayrıca memnuniyetsizlik sebepleri olarak, ağrı, kısa protez ve yumuşak glans sendromu belirtilmiştir. ${ }^{[9]}$ Medikal endüstrideki gelişimlerin şişirilebilir penis protezlerine yansımasıyla, mekanik arızalar günümüzde \%5'lerin altına inmiştir. ${ }^{[16]}$ Bizim 34 olguluk serimizde, şişirilebilir protez implantasyonu yaptığımız bir hastada mekanik problem nedeniyle re-implantasyon yapılmıştır. Çalışmamızda, beş hasta pompa ile ilgili mekanik problem yaşadığını belirtmiştir. Bunlar, hastaların skrotumdaki pompayı bulmada zorluk yaşamaları, özellikle protezi "inflatable" hale getirirken düğmeyi bulamamalarından ötürü duyulan cilt ağrısıdır. Şişirilebilir penil protez implantasyonu yapılan hastalarda, erken dönemde görülen pompayı kullanamamalarına sekonder oluşan skrotal ağrı, analjezik tedavileri ile ortadan kaldırılmıştır. Hastalara protez implantasyonu sonrası 6. haftada aktifleştirme işlemi yapılırken, ayrıntılı olarak pompa kullanımı, protezi şişirme ve söndürme ile ilgili eğitimler tarafımızca verilmiştir.

En korkulan komplikasyon olan penil protez enfeksiyonlarının, her türlü artifisyel materyalde olabildiği bilinmektedir. $^{[17]}$ Enfeksiyonlar, bazen yüzeysel olup antibiyotiklerle tedavi edilebilirken bazen de penil doku kaybına yol açacak kadar dramatik olabilmektedir. ${ }^{[18]}$ Bu tür enfeksiyonlar, penil protez implantasyonunun en kötü komplikasyonlarıdır. ${ }^{[19]}$ En sık enfeksiyon nedeni olan bakteriyel ajan Staphilococcus epidermidis'tir. ${ }^{[19]}$ Literatür incelendiğinde ilk yayınlarda, bükülebilir protezler için $\% 0,6-16,7$ arasında, üç parçalı şişirilebilir protezler için ise $\% 0,8-8$ arasında enfeksiyon oranları bildirilmiştir. ${ }^{[20]}$ Bizim çalışmamızda, iki hastada protez enfeksiyonu nedeniyle penil protez çıkartıldı. Bu hastalardan birinin çıkarılma zamanı protez implantasyonu sonrası 7. ay, diğerinin ise postoperatif 22 . ay idi. Geç dönem protez enfeksiyonu oranını, çalışmamızda literatürle benzer şekilde $\% 5,88$ olarak saptadık. ${ }^{[21]}$ Günümüzde gram pozitif ve gram negatif bakterilere karş1 uygun antibiyotik profilaksisi ve dikkatli cerrahi teknik ile enfeksiyon oranı \%2-3'e düşürülmüştür. ${ }^{[22]}$ Diyabet enfeksiyon için ana risk faktörlerinden biri olarak kabul edilmekte ise de, güncel veriler bu bilgiyi desteklememektedir. ${ }^{[23]}$

Hasta memnuniyeti, birden fazla etkene bağlı olarak ortaya çıkmaktadır; ameliyat öncesi beklentiler, ameliyat sonrası 
ağr1 ve ödem, istenmeyen yan etkiler, protezin işlevselliği, kullanım kolaylığı ve eşler tarafından kabul edilebilirliği gibi faktörlere bağlıdır. ${ }^{[15]}$ Bizim serimizde penil protez implantasyonu, hızlı ve tam bir sertlik sağlaması nedeniyle yüksek memnuniyet oranlarına sahiptir. Bükülebilir penil protez implantasyonu yapılan hastalarımızda, ilk günlerde sürekli rijiditeden kaynaklanan memnuniyetsizlik görülse de zaman içinde bu sorun hasta tarafından kabul görmektedir. Şişirilebilir penil protez implantasyonu yapılan hastalarımızda ise skrotuma yerleştirilen pompanın oluşturduğu rahatsızlık hissi ve ağrı en sık yan etki olarak karşımıza çıksa da, tarafımızdan verilen eğitimlerle hastanın pompayı kullanması sağlanmıştır. Hiçbir hastada memnuniyetsizlik veya kullanamamaya bağlı protez çıkarılması gerekmemiştir.

Literatüre bakıldığında, en yüksek memnuniyet oranlarının ameliyattan sonra 6-12. aylarda olduğu belirtilmiştir. ${ }^{[24]}$ Hasta için uygun protezin seçimi, hastanın olduğu kadar eşinin de memnuniyeti açısından önemlidir. ${ }^{[23,25]}$ Literatürde verilen \%70-87'lik genel memnuniyet oranlarına benzer şekilde, yüksek oranda; yaklaşık \%82,4'lik hasta ve $\% 70,5^{\prime}$ lik partner memnuniyetini saptadık. ${ }^{[26]}$

Çalışmamızda ortalama takip süresi yedi yıldır. Literatürde, penil protez implantasyonu sonrası beş yıl ve üzerinde takip süreleri olan çalışma sayısı azdır. Bu çalışmadaki verilerin geriye dönük olması ve son beş yılda opere edilen hastalarımızın çalışmaya dahil edilmemesi çalışma grubunu kısıtlamıştır. Hastaların bir kısmının çalışmaya katılmayı kabul etmemesi, çalışma veri ve sonuçlarını sınırlandırmaktadır.

\section{SONUÇ}

Organik kökenli ve medikal tedaviye dirençli erektil işlev bozukluğu olgularında, penil protez implantasyonu altın standart olarak yerini korumaktadır. ${ }^{[15]}$ Bu yöntem, uygun hasta seçimi yapıldığı ve antisepsi kurallarına uyulduğunda, düşük yan etkiler, yüksek başarı oranı ve hasta memnuniyeti ile tercih edilmeye devam edecek gibi gözükmektedir. Şişirebilir penil protez seçimi, hastanın sosyokültürel durumuna göre yapılmalıdır. Hastaya, penis protezi ve pompa kullanımı ile ilgili ayrıntılı olarak eğitim verilmelidir.

\section{Hakem Değerlendirmesi}

Dış bağımsız

\section{Çıkar Çatışması}

Yazarlar çıkar ilişkisi olmadığını beyan etmişlerdir.

\section{Peer-review}

Externally peer-reviewed.

\section{Conflict of Interest}

No conflict of interest was declared by the authors.

\section{KAYNAKLAR}

1. Lindau ST, Schumm LP, Laumann EO, Levinson W, O'Muircheartaigh CA, Waite LJ. A study of sexuality and health among older adults in the United States. N Engl J Med 2007;357:762-74. doi: 10.1056/NEJMoa067423

2. NIH Consensus Conference. Impotence. NIH Consensus Development Panel on Impotence. JAMA 1993;270:83-90.

3. Nehra A, Barret DM, Morelan RB. Pharmacotherapeutic advances in the treatment of erectile dysfunction. Mayo Clin Proc 1999;74:709-21. doi: 10.4065/74.7.709

4. Çayan S, Kendirci M, Yaman Ö, Aşçı R, Orhan İ, Usta MF, et al. Prevalence of erectile dysfunction in men over 40 years of age in Turkey: Results from the Turkish Society of Andrology Male Sexual Health Study Group. Turk J Urol 2017;43:122-9. doi: 10.5152/tud.2017.24886

5. Akkus E, Kadioglu A, Esen A, Doran S, Ergen A, Anafarta K, et al. Prevalence and correlates of erectile dysfunction in Turkey: a population-based study. Eur Urol 2002;41:298-304.

6. Mulhall JP, Bella AJ, Briganti A, McCullough A, Brock G. Erectile function rehabilitation in the radical prostatectomy patient. J Sex Med 2010;7:1687-98. doi: 10.1111/j.1743-6109.2010.01804.x

7. Gontero P, Fontana F, Zitella A, Montorsi F, Frea B. A prospective evaluation of efficacy and compliance with a multistep treatment approach for erectile dysfunction in patients after non-nerve sparing radical prostatectomy. BJU Int 2005;95:359-65. doi: 10.1111/j.1464-410X.2005.05300.x

8. Evans $C$. The use of penile prostheses in the treatment of impotence. Br J Urol 1998;81:591-8.

9. Minervini A, Ralph DJ, Pryor JP. Outcome of penile prosthesis implantation for treating erectile dysfunction: experience with 504 procedures. BJU Int 2006;97:129-33. doi: 10.1111/j.1464410X.2005.05907.x

10. Anafarta K. Surgical treatment of erectile dysfunction. Türkiye Klinikleri J Surg Med Sci 2007;3:38-44.

11. Aytac IA. McKinlay JB. Krane RJ. The likely worldwide increase in erectile dysfunction between 1995 and 2025 and some possible policy consequences. BJU Int 1999;84:50-6.

12. Hatzimouratidis $\mathrm{K}$, et al. Guidelines on male sexual dysfunction: erectile dysfunction and premature ejaculation. Eur Urol 2010;57:804-14. doi: 10.1016/j.eururo.2010.02.020

13. Rajpurkar A, Dhabuwala CB. Comparison of satisfaction rates and erectile function in patients treated with sildenafil, intracavernous prostaglandin E1 and penile implant surgery for erectile dysfunction in urology practice. J Urol 2003;170:159-63. doi: 10.1097/01.ju.0000072524.82345.6d

14. Anafarta K, Safak M, Bedük Y, Baltaci S, Aydos K. Clinical experience with inflatable and malleable penile implants in 104 patients. Urol Int 1996;56:100-4.

15. Turna B, Umul M, Altay B, Apaydın E, Semerci B, Çıkılı N. Penil protez yerleştirilmesi cerrahisinde klinik deneyimlerimiz. Türk Ürol Der 2007;33:151-5.

16. Wilson SK, Delk JR, Salem EA, Cleves MA. Long-term survival of inflatable penile prostheses: single surgical group experience with 2384 first-time implants spanning two decades. J Sex Med 2007;4:1074-9. doi: 10.1111/j.1743-6109.2007.00540.x

17. Selph JP, Carson CC 3rd. Penile prosthesis infection: approaches to prevention and treatment. Urol Clin North Am 2011;38:227-35. doi: 10.1016/j.ucl.2011.02.007

18. Carson CC. Penile prosthesis implantation and infection for Sexual Medicine Society of North America. Int J Impot Res 2001;13:S35-8. doi: 10.1038/sj.ijir.3900775 
19. Carson CC. Diagnosis, treatment and prevention of penile prosthesis infection. Int J Impot Res 2003;15:S139-46. doi: 10.1038/sj.ijir.3901091

20. Mould JW, Carson CC. Infectious complications of penile prostheses. Infect Urol 1989;139:50-2.

21. Falcone M, Garaffa G, Gillo A, Dente D, Christopher AN, Ralph DJ. Outcomes of inflatable penile prosthesis insertion in 247 patients completing female to male gender reassignment surgery. BJU Int 2017. doi: 10.1111/bju.14027. [Epub ahead of print]

22. Goldstein I, Newman L, Baum N, Brooks M, Chaikin L, Goldberg $\mathrm{K}$, et al. Safety and efficacy outcome of mentor alpha-1 inflatable penile prosthesis implantation for impotence treatment. J Urol 1997;157:833-9.
23. Montague DK, Angermeier KW. Penile prosthesis implantation. Urol Clin North Am 2001;28:355-61.

24. Mulhall JP, Ahmed A, Branch J, Parker M. Serial assessment of efficacy and satisfaction profiles following penile prosthesis surgery. J Urol 2003;169:1429-33. doi: 10.1097/01. ju.0000056047.74268.9c

25. Montague DK, Angermeier KW. Current status of penile prosthesis implantation. Curr Urol Rep 2000;1:291-6.

26. Levine LA, Estrada CR, Morgentaler A. Mechanical reliability and safety of and patient satisfaction with the Ambicor inflatable penile prosthesis: results of a 2 center study. J Urol 2001;166:932-7. 